\title{
The Assimilation of Immigrants Who Arrived in the United States as Children
}

Jeremy Sandford (E-mail: jeremysandford@yahoo.com), University of Wisconsin: Madison Michael C. Seeborg, (E-mail: mseeborg@iwu.edu), Illinois Wesleyan University

\begin{abstract}
Although there has been much research on the effects of national origin, English speaking ability and educational attainment on the assimilation of immigrants, there has been little work on the effect of age of immigration on assimilation. This paper uses 1990 Census (IPUMS) data to assess the effects of age immigration on the relative earnings performance of 30-year-old immigrant men. Earnings regressions are run for three cohorts of immigrants defined by their age of arrival and a decomposition analysis is conducted to explain earnings gaps between each of the three immigrant cohorts and a sample of nonimmigrant men. We find that immigrants that arrive in the US before their tenth birthday have higher earnings and higher rates of return to education compared to immigrants who arrive at older age. Late arrivals, on the other hand, have a substantial earnings disadvantage relative to natives and seem to be more adversely effected by low levels of ethnic capital. We also found that a substantial income gap remained between older immigrants and natives even after estimating what their earnings would have been had they possessed the native human capital characteristics Age of arrival clearly matters and should be a consideration in designing immigration policy.
\end{abstract}

\section{Introduction}

The ability of immigrants to assimilate into the United States labor market has been a major focus of immigration research. It is well established that national origin, educational attainment and English language proficiency are very important determinants of the ability of immigrants to assimilate. (Borjas 1994, 1999; Chiswick 1978; LaLond and Topel, 1992; Park, 1999). However, there is surprisingly little empirical work beyond descriptive statistics on the effect of age of arrival on the assimilation process. This is a surprising omission since average age of arrival into the United States can be greatly affected by immigration policy.

There are several reasons to expect that immigrants that come to the US as children (i.e., early arrivals) will have an earnings advantage over immigrants that come as adults (i.e., late arrivals). First, most of the formal education of early arrivals is obtained in the US. Since the bulk of US based education is in English with a focus on US culture and institutions, the early arrivals should have higher returns to education than late arrivals. Chiswick and others have shown that that English language proficiency is consistently a significant predictor of earnings for immigrants (Chiswick 1986, 1991; Chiswick and Miller 1999; McMannus 1985).

Second, when early arrivals enter the work force, they should be more capable of competing in mainstream labor markets outside of ethnic communities than late arrivals because they have more years of direct exposure to American culture and institutions. This exposure gives early arrivals greater labor market mobility which should result in an earnings advantage over late arrivals.

Finally, early arrivals could have a significant advantage related to their country of origin compared to late arrivals. Borjas $(1985,1992 a)$ showed that there was a secular decrease in the educational attainment of immigrants since the 1960s as the national origin composition of immigrants changed from Europe toward Latin America and Asia. Early arrivals are more likely to have European parents who have 
Readers with questions or comments please contact the author via email. at least graduated from high school while late arrivals are more likely to have immigrated from Latin America and Asia and to have parents who have not graduated from high school.

An interesting question addressed by our study is whether there is a relationship between age of arrival and ethnic capital in the determination of immigrant earnings. In particular, we ask whether ethnic capital matters more for early arrivals than late arrivals. We argue that the level of ethnic capital is related to age of arrival. The earnings of early arrivals may be less strongly affected by ethnic capital because early arrivals have more time than late arrivals to expand their network of support beyond their own ethnic group. Therefore, early arrivals should have much smaller adverse effects from belonging to an ethnic group with low levels of ethnic capital than late arrivals.

In general, ethnic capital can be defined as the characteristics of a particular immigrant's group that affects the economic performance of that immigrant group. An example would be the group's average educational attainment. It is well documented that an immigrant group's level of ethnic capital plays an important role in determining the ability of immigrants in that group to assimilate (Borjas 1992, 1992a, 1994, 1995, 1999; Sandford and Seeborg, 2002).

Ethnic capital is important because immigrants, upon arrival in the US, may choose to live, work, and socialize with those from their country of origin. Immigrants from groups with low ethnic tend to move into an immigrant neighborhood and thus surround themselves with individuals with low education who may be less likely to speak English well and have lower average earnings. Even the best and the brightest of immigrants from these groups may be pulled back towards the average economic performance of that group. On the other hand, immigrants joining ethnic groups with high social capital tend to be pulled up economically by the favorable external effects from their highly educated, English speaking, and affluent neighbors.

Immigrants may have little choice but to live and work in ethnic enclaves upon arrival; only there can they find people who share their language and culture. However, immigrants who come as children will go to school in the US where they may interact with native children and learn English with native proficiency. They will also have time to absorb US culture through the news media, literature, movies, and music. Immigrants who arrive later in life, especially those who arrive as adults will both be more set in their ways than children and less likely to absorb US culture through schools and societal institutions. Thus we hypothesize that, ceteris paribus, immigrants who arrive early in life will be affected less by the average performance of the ethnic group they join upon immigration than those who arrive later in life.

Our study proxies the level of ethnic capital by the average educational attainment of the immigrant's ethnic group in the US. If the immigrant is a member of an ethnic group that has lower levels of educational attainment than the population in general, his or her economic progress could be slowed. However, if he or she joins a group with high levels of educational attainment, his or her economic performance could be accelerated. Our study includes average educational attainment of the immigrant's ethnic group as a proxy for ethnic capital in the earnings regressions in order to determine its effect on the earnings performance of each of three immigrant age cohorts. We hypothesize that ethnic capital restrains the earnings of early arrivals far less than the ethnic capital of late arrivals.

The remainder of the paper explores the relationship between age of arrival and a set of human capital related variables (educational attainment, English language skills, hours worked and ethnic capital) in the determination of earnings of three immigrant cohorts. Section II defines the database and presents earnings regressions for each of the three immigrant groups. Section III then uses these regression results to conduct an Oaxaca (1973) type decomposition of the earnings differences between each of these three groups and the native nonimmigrant population. Conclusions are given in Section IV.

\section{Age of Arrival and Earnings}


Data are from the 1990 US Census Public Use Microdata Samples (PUMS), made available in the form of IPUMS data by Ruggles and Sobek (1997). Our sample consists of 84,673 US male non-immigrant natives and 11,480 male immigrants. All members of the sample were 30 years old in 1990 when the Census was administered and had incomes of at least $\$ 1,000$.

Unfortunately, PUMS codes age of arrival data in arbitrary, inconsistent intervals. This makes it difficult to know exactly when immigrants arrived and where they received their human capital. This is a significant problem according to Friedman (1997) because without good information on year of arrival it is not possible to determine how much education was received in the country of origin and how much in the United States. As pointed out above, this is important because education received in the US is likely to produce higher returns because it is done in English and it is oriented toward teaching students about American Culture and institutions.

To surmount this problem, our sample includes only 30-year-old men. The available age of arrival data then allows us to split this sample into three groups: those who arrived before their tenth birthday (early arrivals), those who arrived between their tenth and twentieth birthday (middle arrivals), and those who arrived after their twentieth birthday (late arrivals). Another way to think about the sample is that it consists of men who were 30 years old in 1990 with the "early" immigrants arriving during the 1960s the "middle" immigrants arriving during the 1970s and the "late" immigrants arriving during the 1980s. The advantage of this grouping is that we can say something about where each group received their human capital. The early arrivals received most of their education in the US, the late arrivals most abroad, and the middle arrivals have their education split between the US and their country of origin.

Table 1 presents descriptive statistics for non-immigrant natives, early arrivals, middle arrivals, and late arrivals. The dependent variable in our analysis is income from wages and salaries. We are particularly interested in explaining the difference in income between non-immigrant native population and each of the arrival groups (early, middle and late). The income gaps are also presented in Table 1. Explaining these differences will be the focus of the decomposition presented in Section III. Note that the pattern of income differences is consistent with the arguments presented above where we expected early arrivals to be at a relative advantage compared to later arriving immigrants. Using natives as the reference group, we see that late arrivals trail natives by more than $\$ 7,000.00$ while early arrivals actually have an earnings advantage over natives of more than $\$ 1,000.00$.

Table 1: Descriptive Statistics for Natives and Immigrants by Age of Arrival

\begin{tabular}{lllll}
\hline & Natives & Early Arrivals & Middle Arrivals & Late Arrivals \\
\hline Wage and Salary Income & $\$ 25,280.44$ & $\$ 26,572.55$ & $\$ 21,926.96$ & $\$ 17,884.83$ \\
Difference from natives & N/A & $-\$ 1,292$ & $\$ 3,353$ & $\$ 7,395$ \\
High School (percent) & $64.1 \%$ & $59.6 \%$ & $34.1 \%$ & $35.4 \%$ \\
College (percent) & $22.9 \%$ & $28.7 \%$ & $15.7 \%$ & $24.86 \%$ \\
Ethnic Capital* $^{*}$ & 0 & -.43 years & -3.23 years & -2.08 years \\
Speaks very well & $98.8 \%$ & $94.4 \%$ & $47.8 \%$ & $37.4 \%$ \\
Hours worked & $2,130.82$ & $2,134.11$ & $2,014.73$ & $1,881.54$ \\
Sample size & 84,673 & 1,114 & 2,706 & 4,690 \\
\hline
\end{tabular}

*Since ethnic capital is defined as the difference between a group's average educational attainment and that of natives, native ethnic capital is set to 0 .

Table 1 also presents summary statistics for the independent variables, including educational attainment, language proficiency, and hours worked. Variable definitions are given in Table 2. HS_GRAD is a dichotomous dummy variable equaling 1 if the individual has a high school education but not a college degree. COLLEGE equals 1 if and only if the individual graduated from college.

VERYWELL is a dichotomous dummy variable measuring English language proficiency. It is equal to 1 if the individual listed himself as speaking English "very well" or speaking only English. It is set to 0 if the 
individual listed himself as speaking "well" or below. While we acknowledge the limitation of using selfreported language data, Chiswick (1991) and Chiswick and Miller (1999) have used similar measures with significant results.

ETHNIC_CAP is a proxy for social capital. We follow Borjas (1992) in defining the proxy as the difference between average native educational attainment and the average educational attainment of the national group an immigrant joins upon arriving in the US. We used Borjas (1994) tabulations of ethnic capital values and merged them into our data set. Ethnic capital values are listed in Table A for each

Table 2: Variable Definitions

\begin{tabular}{ll}
\hline Variable & Definition \\
\hline $\begin{array}{l}\text { Dependent: } \\
\text { INCOME }\end{array}$ & 1989 annual income from wages and salaries. \\
ETHNIC_CAP & $\begin{array}{l}\text { The difference between the educational attainment of immigrants from respondent's } \\
\text { country of origin relative to mean education of native men. }\end{array}$ \\
VERYWELL & Equals 1 if immigrant rated himself as speaking English very well \\
COLLEGE & Equals 1 if the immigrant has a college degree \\
HS_GRAD & Equals 1 if the immigrant has a HS degree, but not a college degree \\
HOURS & Total hours worked for the year for which income is reported \\
\hline
\end{tabular}

country of origin. These scores range from -5.59 years for the 2,054 respondents from Mexico to 2.74 years for the 273 respondents from India. Unfortunately, these tabulations do not span all the countries of origin in our sample; so 2,959 immigrants were dropped from the sample. Sample sizes listed in Table 1 reflect all dropped cases.

HOURS is a proxy for total hours worked for the year for which income is reported. It measures the intensity of work experience. Those who work more hours may also have the opportunity to receive more onthe-job training.

Table 1 shows that immigrants from our sample of 30 year old men who arrived before the age of 10 (early arrivals) were much more likely to have graduated from high school than immigrants who arrived between the ages of 10 and 20 (middle arrivals) and those who arrived between the ages of 20 and 30 (late arrivals). Early arrivals also were more likely to have achieved a college degree than middle and late arrivals. Indeed, "early" arrivals have a pattern of educational attainment that more closely parallels the educational attainment of natives than "middle" or "late" arrivals. Not surprisingly, early arrivals are much more likely to have self reported that they spoke English very well and to report more hours of work for calendar year 1989 than the other immigrant groups.

Table 1 also shows that early arrivals have significantly higher levels of ethnic capital than the other two immigrant groups, where ethnic capital is defined as the difference between the mean educational attainment of immigrants from the respondent's country of origin relative to the mean educational attainment of native men. This is because the immigrants that arrived in the 1960s (i.e, early arrivals) have a higher percentage of Europeans than immigrants who arrived in the 1970s (middle arrivals) and 1980s (late arrivals). Because the European immigrants joined ethnic communities with higher levels of educational attainment, the early arrivals have an advantage in ethnic capital relative to the later arriving immigrants. 
In sum, the pattern of human capital acquisition of early arrivals more closely resembles that of natives than the other two immigrant groups. Early arrivals have similar average earnings to natives and they also have similar levels of human capital. The middle arrivals and the late arrivals, on the other hand, appear to lag behind both the natives and the early arrivals. The following pages examine these relationships in more detail using earnings regressions and decomposition analysis.

We know from the descriptive statistics in Table 1 that early arrival immigrants have higher levels of education, are more likely to speak English well, and earn somewhat more than middle and late arrivals. As argued earlier, we also expect that early arrivals to have higher returns to their human capital in the labor market. Thus, we hypothesize that the human capital that early-arriving immigrants acquire will be more valuable upon reaching the labor market than that possessed by later-arriving immigrants. In order to determine the returns to human and ethnic capital of the three immigrant groups, a separate regression was run for each group, using annual wage and salary income as the dependent variable and the five variables defined in Table 2 as the independent variables.

We hypothesize that, since early arrivals have obtained most of their education in the United States, they should have greater returns to educational attainment (HS_GRAD and COLLEGE) than "middle" and "late" arrivals.

We also expect that coefficients to the ethnic capital variable (ETHNIC_CAP) should be lower for "early" arrivals relative to the other two immigrant groups because the "early" arrivals have more time to acquire U.S. specific human capital and thus are less dependent upon ethnic communities for support.

Hours worked (HOURS) is a control variable. We expect the coefficient to HOURS to be larger for early arrivals because they have higher levels of U.S. specific human capital and thus an additional hour of work should result in a larger increase in earnings for "early" arrivals than for the other two immigrant groups.

Finally, we expect the sign for the English language proficiency variable to be positive and significant for all three Immigrant groups. We have no expectation for the relative magnitude of the coefficient across the three groups.

The regression results, which are presented in Table 3, generally support our hypotheses. Child immigrants (i.e., early arrivals) have much greater returns to educational attainment (HS_GRAD and COLLEGE) compared to those who arrived at a later age (middle arrivals and late arrivals). This is not surprising since early arrivals received most of their formal education in the United States while late arrivals received most of their education in their countries of origin. Where immigrants receive their education is clearly an important determinant of the returns to education.

The effects of hours worked on income across the three groups is also consistent with expectations, with early arrivals having a significantly higher return for additional hours worked, even after controlling for educational attainment, English language proficiency and Ethnic Capital. English language proficiency (VERYWELL) is a significant and positive predictor for the middle and late arrivals, but insignificant for the early arrivals. The VERYWELL coefficient in the early regression may be insignificant because $94.4 \%$ of early arrivals speak English very well, and those who don't may have other factors affecting their earnings.

Table 3: Annual Earnings Regression Results for Immigrants by Age of Arrival

\begin{tabular}{llll}
\hline & Early Arrivals & Middle Arrivals & Late Arrivals \\
\hline HS_GRAD & $4,410.723$ & $3,438.427$ & $1,832.534$ \\
& $(2.46)$ & $(4.10)$ & $(3.76)$ \\
COLLEGE & $15,279.139$ & $11,418.648$ & $7,038.023$ \\
& $(7.74)$ & $(9.33)$ & $(11.22)$ \\
ETHNIC_CAP & -220.339 & 854.459 & 812.525
\end{tabular}




\begin{tabular}{llll} 
& $(-.92)$ & $(5.75)$ & $(10.17)$ \\
VERYWELL & -343.416 & $1,642.261$ & $3,895.582$ \\
& $(-.14)$ & $(2.25)$ & $(9.13)$ \\
HOURS & 10.172 & 7.335 & 7.561 \\
& $(12.59)$ & $(14.99)$ & $(28.90)$ \\
Adjusted R^2 & .21 & .21 & .29 \\
Sample Size & 1,114 & 2,706 & 4,690 \\
\hline
\end{tabular}

\section{Decomposition of Native/Immigrant Income Differences}

The purpose of the decomposition analysis is to explain the differences in mean annual income from wages and salaries between non-immigrant native men and each of the three immigrant groups. To do this, an Oaxaca (1973) style decomposition procedure is applied to our 1990 PUMS sample of 30-year-old men. These differences in mean annual wage and salary income are presented in Table 4. They range from an earnings advantage of natives over late arrivals of $\$ 7,395$ to an earnings disadvantage of natives compared to late arrivals of $\$ 1292$. Why do late arrivals fair so poorly relative to natives while early arrivals fair so well relative to natives. Part of the explanation may be that there are different levels of educational attainment, English language proficiency, and ethnic capital and hours worked between each of the immigrant groups and the natives. The other part of the explanation is that the returns to educational attainment, English language proficiency, ethnic capital and hours worked may be different between the groups. The results of the decomposition analysis are presented in Table 4.

Table 4: Native - Immigrant income gaps decomposed by human capital

\begin{tabular}{llll}
\hline & Early Arrivals & Middle Arrivals & Late Arrivals \\
\hline Initial Gap & $-\$ 1,292$ & $\$ 3,353$ & $\$ 7,395$
\end{tabular}

Percentage of above gaps closed by inserting native human capital means into immigrant equations:

\begin{tabular}{llll} 
HS & $15.3 \%$ & $30.8 \%$ & $7.1 \%$ \\
COLLEGE & $68.6 \%$ & $24.4 \%$ & $-1.8 \%$ \\
ETHNIC_CAP & $7.4 \%$ & $82.4 \%$ & $22.9 \%$ \\
VERY WELL & $1.2 \%$ & $25.0 \%$ & $32.3 \%$ \\
HOURS & $2.6 \%$ & $25.4 \%$ & $25.5 \%$ \\
\hline Total & $64.4 \%$ & $188.0 \%$ & $85.9 \%$ \\
\hline
\end{tabular}

In the decomposition analysis we estimate what fraction of the earnings difference between natives and each of the immigrant groups that comes from differences in educational attainment, English language proficiency, ethnic capital, and hours worked, and what fraction comes from differences in returns to these earnings determinants.

An Oaxaca (1973) style decomposition is used to explain the differences in mean annual wage and salary income between natives and each of the three immigrant groups. We start by regressing wage and salary income against variables measuring educational attainment, English language proficiency, ethnic capital, and hours worked. Three regressions are run, one for early arrivals, one for middle arrivals, and one for late arrivals.

We decompose the native-immigrant income differentials by starting with the regression equation of an immigrant group and substituting native means for the immigrant means. For example, to decompose the earnings gap between late arrivals and natives, we start with the late arrivals regression, equation (1). Let the subscript $\mathrm{N}$ represent native values and the subscript $\mathrm{L}$ represent values for the late arrivals. 


$$
\begin{gathered}
\text { INCOME }_{\mathrm{L}}=\alpha_{1}+\beta_{11} * \mathrm{HS}_{-} \text {GRAD }_{\mathrm{L}}+\beta_{12} * \text { COLLEGE }_{\mathrm{L}}+\beta_{13} * \text { ETHNIC_CAP }_{\mathrm{L}}+ \\
\beta_{14} * \operatorname{VERYWELL}_{\mathrm{L}}+\beta_{15} * \operatorname{HOURS}_{\mathrm{L}}
\end{gathered}
$$

We then substitute in native means one at a time until we end up with equation (2).

$$
\begin{aligned}
& \text { INCOME }_{\mathrm{N}}=\alpha_{1}+\beta_{11} * \mathrm{HS}_{\mathrm{N}}+\beta_{12} * \text { COLLEGE }_{\mathrm{N}}+\beta 13 * \mathrm{ED}_{-} \mathrm{CAP}_{\mathrm{N}}+ \\
& \beta_{14} * \text { VERYWELL }_{\mathrm{N}}+\beta_{15} * \operatorname{HOURS}_{\mathrm{N}}
\end{aligned}
$$

Subtracting (2) from (1) yields equation (3).

(3) $\mathrm{INCOME}_{\mathrm{L}}-\mathrm{INCOME}_{\mathrm{N}}=$ native - late gap explained by differences in levels

The residual gap is then the part of the income gap between natives and late arrivals explained by differences in returns to human capital.

The same procedure is used to decompose the income gap between natives and middle arrivals and the income gap between natives and early arrivals.

These decomposition results predict that if immigrants were to acquire human capital and language on par with natives, were to shed their ethnic capital, and were to work the same number of hours as natives, the gaps between natives and immigrants would change considerably. Early arrivals, who on average earn \$1,292 more than natives, would see that earnings advantage depleted by $64.37 \%$. Middle arrivals, which make an average of $\$ 3,353$ less than natives, would see their earnings shoot up past the native mean, covering $187.96 \%$ of the original gap. Late arrivals, who on average earn $\$ 7,396$ less than natives, would see $85.94 \%$ of this gap closed if they were to have native means.

Since the residual gap, that attributable to differences in returns to human capital, is small for early arrivals and late arrivals and negative for middle arrivals, our results predict that differences in human capital levels are the prime most important cause of the earnings gaps between natives and immigrants. Table 4 breaks down these differences still further; the five rows labeled with the five human capital variables (HS, COLLEGE, ED_CAP, VERYWELL and HOURS) list the percentage of the earnings gap between natives and immigrants explained by each individual human capital consideration. For example, Table 4 suggests that removing the large educational gap between early arrivals and natives removes $68.6 \%$ of the earnings gap.

On the other hand, not much of the income gap between natives and late arrivals is explained by differences in educational attainment between the two groups. The earnings advantage that natives have over late arrivals seems to be largely due to disadvantages that late arrivals have in terms of English speaking ability, hours worked and less favorable levels of ethnic capital. Put differently, most of the earnings differentials between these two groups can be explained by substituting native means for ETHNIC_CAP, VERYWELL AND HOURS into the late arrivals regression equation.

Substituting native means into the middle arrivals equation causes middle earnings to well overshoot the native average. Much of this change comes from ethnic capital. Middle arrivals have a low average ethnic capital of -3.23 years, and substituting in the native ethnic capital value of 0 bridges $82.4 \%$ of the earnings gap between natives and middle arrivals. That middle arrivals overshoot the native earnings mean with native human capital means suggests that middles see much higher returns to human capital than natives do, they just in general have lower levels of human capital. This is an unexpected result; it is possible that the middle group has higher returns because the immigrants who comprise this group immigrated when they were young enough to lean English with native proficiency and to absorb US culture and influences valuable upon reaching the labor market but also old enough to have a well-developed first language and culture that could also be valuable to global corporations. Thus we suggest that this unexpected result is attributable to a labor market reward to bilingualism and multiculturalism.

\section{Conclusions}

In sum, for our sample of 30-year-old immigrants, age of immigration is extremely important. Early arrivals have advantages over immigrants who arrive later. They end up with higher levels of educational attainment, 
possess higher amounts of ethnic capital, and are much more likely to be very proficient in English. These advantages cause their annual wage and salary income to be greater than for all other groups, including nonimmigrant natives. When the early arrivals were assigned the same characteristics as natives in the decomposition exercise, their estimated annual income decreased, but still remained above natives. This remarkable result implies that immigrants who come as youth suffer no disadvantages in the labor market. Late arrivals, on the other hand, have a substantial earnings disadvantage relative to natives. Further, we found that a substantial income gap remained after assigning the late group the more favorable native characteristics in the decomposition exercise. Age of arrival clearly matters and should be a consideration in designing immigration policy.

\section{References:}

1. Borjas, George J. "Assimilation, changes in Cohort Quality, and the Earnings of Immigrants.” Journal of Labor Economics, 3 October 1985, 3(4), pp. 463-89.

$2 . \quad$. "Ethnic Capital and Intergenerational Mobility." Quarterly Journal of Economics, February 1992, 107(1), pp.123-150.

3. _. _ _National Origin and the Skills of Immigrants in the Postwar Period," in G.J. Borjas and R. Freeman, eds., Immigration and the Work Force. Chicago, IL: U. of Chicago Press, 1992a, pp. 17-47.

4. _ _ _ "The Economics of Immigration." Journal of Economic Literature, December 1994, 32(4), pp. 1667-1717.

5. $\quad$. Ethnicity, Neighborhoods, and Human-Capital Externalities." American Economic Review, June 1995, 85(3), pp. 365-390.

$6 . \quad$ Heaven's Door: Immigration Policy and the American Economy. Princeton, NJ: Princeton University Press, 1999.

7. Chiswick, Barry R. "The Effect of Americanization on the Earnings of Foreign-Born Men." Journal of Political Economy, October 1978, 86(5), pp. 893-921.

8. _. "Is the New Immigration Less Skilled Than the Old?" Journal of Labor Economics, April 1986, 4(2), pp.186-92.

$9 . \quad$ _. "Speaking, Reading, and Earnings Among Low-Skilled Immigrants." Journal of Labor Economics, April 1991, 9(2), pp. 149-170.

10. Chiswick, Barry R. and Miller, Paul. "Language Skills and Earnings Among Legalized Aliens.” Journal of Population Economics, February 1999, 12(1), pp. 63-89.

11. De Coulon, A. "Wage Differentials between Ethnic Groups." Labour, March 2001, 15(1), pp. 111-132.

12. Friedberg, Rachal M. "You Can't Take it With You? Immigrant Assimilation and the Portability of Human Capital." Journal of Labor Economics, April 2000, 18(2), pp. 221-252.

13. LaLond, Robert J. and Topel, Robert H. "The Assimilation of Immigrants in the U.S. Labor Market." .In Immigration and the Work Force, edited by George J. Borjas and Richard Freeman. Chicago, IL: U. of Chicago Press, 67-92, 1992.

14. McManus, Walter S. "Labor Market Costs of Language Disparity: An Interpretation of Hispanic Earnings Differences." American Economic Review, September 1985, 75(4), pp. 818-827.

15. Oaxaca, Ronald. "Male-Female Wage Differentials in Urban Labor Markets." Review of Economics and Statistics, October 1973, 14(3), pp.693-709.

16. Park, Jin. "The Earnings of Immigrants in the United States: The Effect of English-Speaking Ability." American Journal of Economics \& Sociology, January 1999, 58(1), pp. 43-57.

17. Ruggles, Steven and Sobek, Matthew. Integrated Public Use Microdata Series: Version 2.0. Minneapolis: Historical Census Projects, University of Minnesota, 1997.

18. Sandford, Jeremy and Seeborg, Michael. "The Effects of Ethnic Capital and Age of Arrival on the Standard of Living of Young Immigrants.” The Journal of Economics, forthcoming, 2002. 
Table A-1: Ethnic Capital levels by Country of Origin

\begin{tabular}{|c|c|c|}
\hline Country & Ethnic Capital* & Sample Size \\
\hline \multicolumn{3}{|l|}{ Europe } \\
\hline Austria & 1.48 & 7 \\
\hline Czechoslovakia & 1.26 & 12 \\
\hline France & 1.56 & 110 \\
\hline Germany & .68 & 342 \\
\hline Greece & -1.37 & 61 \\
\hline Hungary & .39 & 5 \\
\hline Italy & -2.3 & 116 \\
\hline Poland & -.43 & 114 \\
\hline Portugal & -4.91 & 56 \\
\hline U.S.S.R. & 1.03 & 59 \\
\hline United Kingdom & 1.40 & 204 \\
\hline Yugoslaavia & -1.45 & 39 \\
\hline \multicolumn{3}{|l|}{ Asia } \\
\hline Cambodia & -2.98 & 53 \\
\hline China & -.38 & 172 \\
\hline India & 2.74 & 273 \\
\hline Iran & 2.32 & 74 \\
\hline Japan & 1.98 & 238 \\
\hline Korea & 1.05 & 189 \\
\hline Laos & -3.22 & 90 \\
\hline Lebanon & .96 & 48 \\
\hline Philippines & .85 & 320 \\
\hline Taiwan & 3.12 & 144 \\
\hline Vietnam & -.94 & 246 \\
\hline \multicolumn{3}{|c|}{ North and South America } \\
\hline Argentina & .15 & 45 \\
\hline Canada & .59 & 266 \\
\hline Colombia & -1.12 & 168 \\
\hline Cuba & -1.46 & 271 \\
\hline Dominican Republic & -2.92 & 149 \\
\hline Ecuador & -1.65 & 84 \\
\hline El Salvador & -4.59 & 321 \\
\hline Guatemala & -3.97 & 137 \\
\hline Haiti & -1.98 & 117 \\
\hline Jamaica & -1.23 & 97 \\
\hline Mexico & -5.59 & 2,044 \\
\hline Nicaragua & -1.47 & 108 \\
\hline Peru & -.21 & 89 \\
\hline \multicolumn{3}{|l|}{ Africa } \\
\hline Egypt & 2.42 & 38 \\
\hline Ethiopia & .77 & 31 \\
\hline Nigeria & 2.60 & 95 \\
\hline South Africa & 2.71 & 15 \\
\hline Australia & 2.01 & 26 \\
\hline
\end{tabular}


$\underline{\text { Notes }}$ 